\title{
Preoperative Magnetic Resonance Cholangiopancreatography for Detecting Difficult Laparoscopic Cholecystectomy in Acute Cholecystitis
}

\author{
Kojiro Omiya *(D), Kazuhiro Hiramatsu, Yoshihisa Shibata, Masahide Fukaya, Masahiro Fujii, Taro Aoba, \\ Atsuki Arimoto, Takayuki Yamaguchi and Takehito Kato
}

\section{check for} updates

Citation: Omiya, K.; Hiramatsu, K.; Shibata, Y.; Fukaya, M.; Fujii, M.; Aoba, T.; Arimoto, A.; Yamaguchi, T.; Kato, T. Preoperative Magnetic Resonance Cholangiopancreatography for Detecting Difficult Laparoscopic Cholecystectomy in Acute Cholecystitis. Diagnostics 2021, 11, 383. https://doi.org/10.3390/ diagnostics11030383

Academic Editor: Bogdan Socea

Received: 13 February 2021

Accepted: 20 February 2021

Published: 24 February 2021

Publisher's Note: MDPI stays neutral with regard to jurisdictional claims in published maps and institutional affiliations.

Copyright: (c) 2021 by the authors. Licensee MDPI, Basel, Switzerland. This article is an open access article distributed under the terms and conditions of the Creative Commons Attribution (CC BY) license (https:/ / creativecommons.org/licenses/by/ $4.0 /)$.
Department of General Surgery, Toyohashi Municipal Hospital, 50 Hakken-Nishi, Aotake-Cho, Toyohashi City, Aichi Prefecture 440-8570, Japan; hiramatsu-kazuhiro@toyohashi-mh.jp (K.H.); shibata-yoshihisa@toyohashi-mh.jp (Y.S.); fukaya-masahide@toyohashi-mh.jp (M.F.); fujii-masahiro@toyohashi-mh.jp (M.F.); aoba-taro@toyohashi-mh.jp (T.A.); arimoto-atsuki@toyohashi-mh.jp (A.A.); yamaguchi-takayuki@toyohashi-mh.jp (T.Y.); kato-takehito@toyohashi-mh.jp (T.K.)

* Correspondence: ksktomiya@gmail.com; Tel.: +81-532-33-6111

\begin{abstract}
Previous studies have shown that signal intensity variations in the gallbladder wall on magnetic resonance imaging (MRI) are associated with necrosis and fibrosis in the gallbladder of acute cholecystitis (AC). However, the association between MRI findings and operative outcomes remains unclear. We retrospectively identified 321 patients who underwent preoperative magnetic resonance cholangiopancreatography (MRCP) and early laparoscopic cholecystectomy (LC) for AC. Based on the gallbladder wall signal intensity on MRI, these patients were divided into high signal intensity (HSI), intermediate signal intensity (ISI), and low signal intensity (LSI) groups. Comparisons of bailout procedure rates (open conversion and laparoscopic subtotal cholecystectomy) and operating times were performed. The recorded bailout procedure rates were $6.8 \%$ ( $7 / 103$ cases), $26.7 \%$ (31/116 cases), and $40.2 \%$ (41/102 cases), and the median operating times were 95, 110, and 138 minutes in the HSI, ISI, and LSI groups, respectively (both $p<0.001$ ). During the multivariate analysis, the LSI of the gallbladder wall was an independent predictor of both the bailout procedure (odds ratio [OR] 5.30; 95\% CI 2.11-13.30; $p<0.001$ ) and prolonged surgery ( $\geq 144 \mathrm{~min}$ ) (OR 6.10, 95\% CI 2.74-13.60, $p<0.001)$. Preoperative MRCP/MRI assessment could be a novel method for predicting surgical difficulty during LC for AC.
\end{abstract}

Keywords: acute cholecystitis; cholecystectomy; MRCP; MRI

\section{Introduction}

Acute cholecystitis (AC) is one of the most common surgical emergencies in the world. The Tokyo Guidelines propose that the treatment strategy should be considered and chosen according to the severity. Early laparoscopic cholecystectomy (LC) soon after onset is recommended as the first choice of treatment for patients with grade I (mild) and grade II (moderate) AC and for selected patients with grade III (severe) AC [1]. However, severe intraoperative complications such as bile duct injury occur at a certain rate in LC [2,3]. Given the number of daily surgeries performed, preoperative assessment to prevent intraoperative complications in each case is crucial. Surgical difficulty due to severe inflammation and an anatomical anomaly of the bile duct, such as an aberrant posterior sectoral hepatic duct (PHD), are the most common causes of serious complications, such as bile duct injury, during LC [2,4-6]. In addition, 7.7-14.3\% of patients with AC have concomitant common bile duct stones, which need to be treated with 1-stage or 2-stage treatment management [7-9]. To determine the appropriate treatment strategy and perform subsequent early LC safely, the surgeon needs the ability to predict the surgical difficulty of 
LC and assess the biliary anatomy in a limited amount of time before surgery, especially in emergency conditions.

Magnetic resonance cholangiopancreatography (MRCP) is now widely used to noninvasively assess the biliary tract anatomy without a contrast agent. MRCP is useful for diagnosing biliary disease and its cause, such as common bile duct stones. Additionally, a recent retrospective study reported that MRCP effectively assessed the aberrant PHD, which is frequently injured during LC [10]. Meanwhile, Jung et al. [11] have highlighted that half-Fourier acquisition single-shot turbo spin-echo (HASTE) magnetic resonance imaging (MRI) of AC captured during MRCP typically reveals two layers in the gallbladder wall: A low signal inner layer of mucosa and muscle and a high signal outer layer of serosal edema. Our previous study revealed that the thickening of the inner layer with a low signal was associated with significant inflammatory pathological changes in the gallbladder wall, such as necrosis and fibrosis, which substantially impact the surgical difficulty of LC [12]. Thus far, using rates of bailout procedures (such as open conversion and laparoscopic subtotal cholecystectomy) and the operating time as indicators, numerous studies have identified predictors for surgical difficulty during early LC for AC. However, the relationship between MRI findings and the surgical outcome of early LC for AC has not been clarified. If a surgical difficulty prediction method using HASTE MRI were to be established, MRCP might become the best evaluation method for the comprehensive surgical management of AC and decision making when there is limited time before surgery.

The present study investigated the association between signal intensity variations in gallbladder walls on MRI and surgical outcomes in patients who underwent early LC for AC to elucidate the utility of MRCP for predicting surgical difficulty.

\section{Materials and Methods}

This retrospective single-institution study was performed to discern the association between preoperative MRI findings and surgical outcomes of early LC in patients with AC at Toyohashi Municipal Hospital in Japan between January 2010 and December 2019. The ethics committee of Toyohashi Municipal Hospital approved the study protocol (approval number 569).

\subsection{Patients}

We searched an institutional surgery database to identify eligible patients, and we collected patient information from the electronic medical records. The eligibility criteria were as follows: (1) AC clinically diagnosed according to the Tokyo Guidelines of 2007 [13], 2013 [14], and 2018 [15]; (2) having undergone LC $\leq 7$ days from disease onset (early LC); and (3) having undergone MRCP/MRI $\leq 24 \mathrm{~h}$ before surgery. Study exclusion criteria included (1) a gallbladder wall thickness of less than $3 \mathrm{~mm}$ on MRI and (2) the clinical suspicion of gallbladder cancer.

During the study period, computed tomography (CT) was performed for all patients clinically suspected of having AC, for the differential diagnosis and an assessment of the general condition. Surgical indications for AC and types of surgery followed the Tokyo Guidelines in principle, but were ultimately decided on a case-by-case basis by the surgeon. Most of the patients who presented at $72 \mathrm{~h}$ or later after onset underwent elective surgery according to the 2013 Tokyo Guidelines [16]. Preoperative MRCP on a 3-T superconducting instrument (MAGNETOM Skyra; Siemens, Erlangen, Germany) was routinely performed on patients diagnosed with AC who were scheduled to undergo early LC to assess the presence of common bile duct stones and abnormal anatomical variations in the bile duct before surgery. If the Calot's triangle anatomy was unclear due to severe inflammation in intraoperative findings, bailout procedures such as open conversion or laparoscopic subtotal cholecystectomy were considered. The details of each surgery, such as the type of surgery, intraoperative biliary injury, intraoperative accidental injury of the gallbladder, and degree of inflammation as intraoperatively determined by the surgeon, were routinely 
recorded in the surgical record based on a questionnaire that was administered as soon as the surgery was completed.

\subsection{MRI Assessment}

HASTE T2-weighted MRI scans were captured during MRCP for all eligible patients and were retrospectively and independently assessed by two surgeons (K. O. and K. H.), who were blinded to the clinical information and type of surgery, but were aware that cholecystitis was present in each case. The gallbladder wall thickness was measured from the section showing the thickest part of the wall. Based on the layered pattern of the thickened wall, patients were divided into three groups as follows (Figure 1):

1. A high signal intensity (HSI) group having two layers with a discrete margin composed of a thin inner layer $(\leq 3 \mathrm{~mm})$ with a low signal and a relatively thick outer layer with a high signal;

2. An intermediate signal intensity (ISI) group having two layers with a partially illdefined margin composed of a partially thickened inner layer $(>3 \mathrm{~mm}$ ) with a low signal and an outer layer with a high or partially heterogeneous intermediate signal;

3. A low signal intensity (LSI) group having ill-defined layers composed of a diffusely thickened inner layer ( $>3 \mathrm{~mm}$ ) with a low signal and an outer layer with an intermediate to low signal.
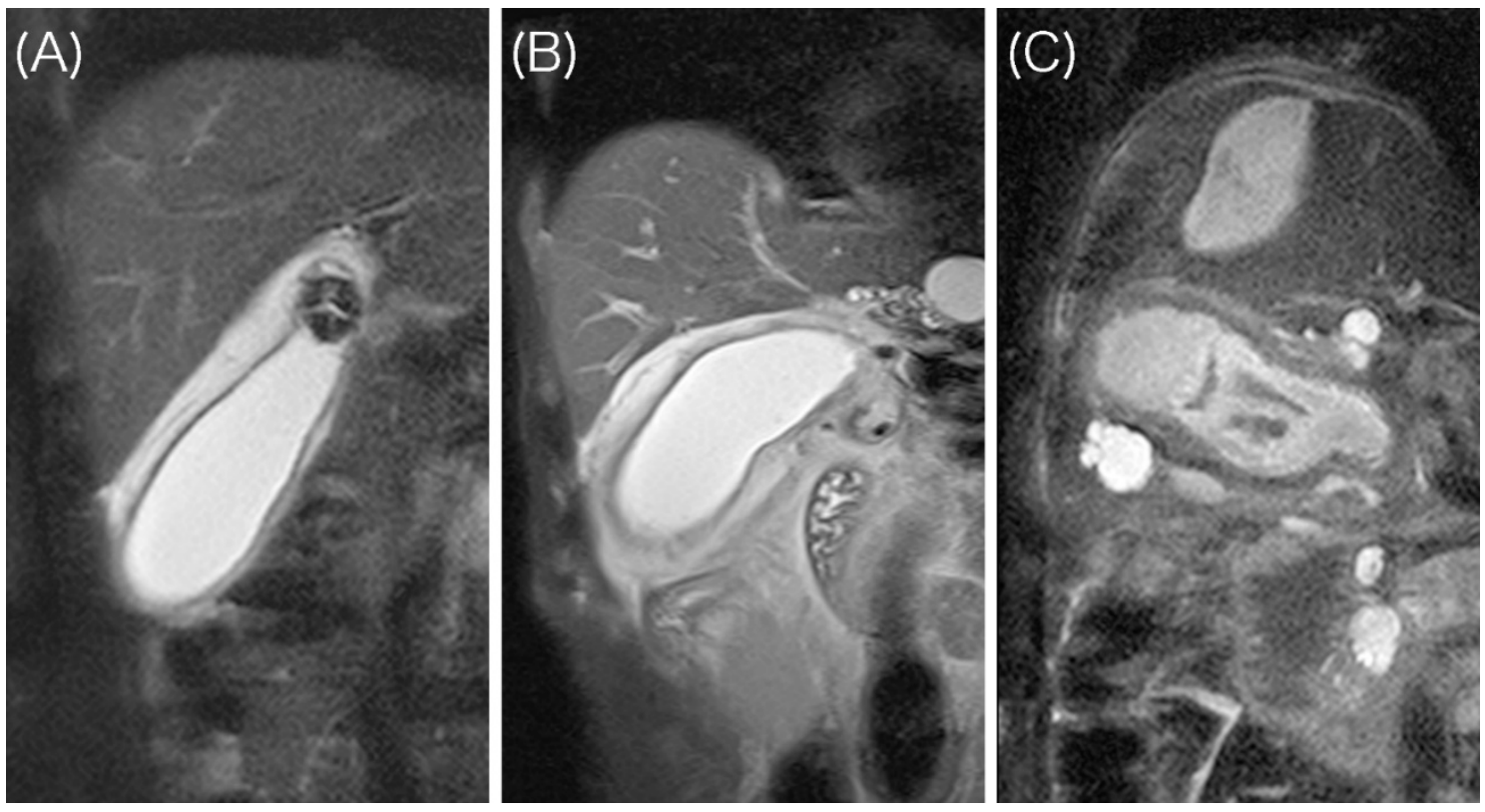

Figure 1. Layered pattern of the gallbladder wall. (A) High signal intensity (HSI) type: Thin inner layer with a low signal intensity, thickened outer layer with a high signal intensity, and well-defined margin; (B) intermediate signal intensity (ISI) type: Partially thickened inner layer, intermediate signal intensity in the outer layer, and ill-defined margin; (C) low signal intensity (LSI) type: Diffusely thickened low signal intensity layer.

This classification scheme was the same as that used in our previous study [12]. We determined the signal intensities by adopting standardized regions of interest. The size of the region of interest was similar for all measurements and patients and varied between 0.03 and $0.06 \mathrm{~cm}^{2}$. We judged LSI lesions of the gallbladder wall relative to the renal parenchyma's signal intensity level. 


\subsection{Outcomes}

\subsubsection{Primary Outcomes}

The primary outcomes of the study were the "bailout procedures" rate, defined as open conversion of the initial laparoscopic approach and laparoscopic subtotal cholecystectomy, and the operating time. Laparoscopic subtotal cholecystectomy was defined as gallbladder resection with a laparoscopic linear stapler at the gallbladder neck. The outcomes among the three groups were compared.

\subsubsection{Secondary Outcomes}

Secondary outcomes of the study were blood loss, intraoperative biliary injury, intraoperative accidental injury to the gallbladder, a postoperative hospital stay, reoperation, readmission, and the incidence rate of postoperative complications. Clavien-Dindo scoring was used to grade the postoperative complications. The overall postoperative complication rate was defined as that occurring in grades II to $\mathrm{V}$, and major postoperative complications were defined as grades III to V. Additionally, we reviewed intraoperative finding records on the degree of inflammation, as evaluated by the surgeon. The outcomes among the three groups were compared.

\subsection{Identification of Predictors for Increased Surgical Difficulty}

We assessed the layered pattern of the gallbladder wall on MRI and other factors potentially predictive of surgical difficulty that had previously been reported [17-27] to identify predictive factors for the bailout procedures and prolonged operating times. These included a male sex, age, the body mass index (BMI), the body temperature, diabetes, gallbladder wall thickening, incarcerated stones in the gallbladder neck, fluid retention around the gallbladder, the white blood cell (WBC) count, the C-reactive protein (CRP) level, the albumin level, the total bilirubin level, the severity grade according to the Tokyo Guidelines [13-15], and the time between disease onset and surgery. A prolonged operating time was defined as the third quartile of the operating time of the entire study group. Severe inflammation findings detected on CT were also compared, such as irregular thickening of the gallbladder wall, poor contrast enhancement of the gallbladder wall, an increased density of fatty tissue around the gallbladder, membranous structures within the lumen, and an abscess around the gallbladder. These CT findings were reported as indicators of gangrenous cholecystitis in the study by Bennett et al. [28]. In addition, we assessed the surgeon's previous experience because some studies have suggested that the operating time greatly varies, depending on the operator's skill and experience [29-31].

\subsection{Statistical Analysis}

Continuous variables are presented as medians and interquartile ranges, whereas categorical variables are presented as numbers of patients and percentages. All $p$-values are two-sided, and associations were considered significant at $p<0.05$. Differences in categorical variables were tested using Fisher's exact test. The Kruskal-Wallis rank-sum test was used to detect differences in continuous variables among the three signal intensity groups. If there was a significant difference between the three groups, pairwise comparisons for all groups were performed, with $p$-values adjusted using the Holm method.

A univariate analysis with independent variables was performed to identify independent risk factors for bailout procedures and prolonged operating times. Continuous variables were dichotomized based on institutional reference values or the first or third quartile of the entire study group. Those variables with $p \leq 0.1$ in the univariate analysis were entered into multivariable logistic regression models. The discrimination power of the logistic regression model was summarized using the C-index.

All statistical analyses were performed using $R$ version 3.5.2 ( $R$ Foundation for Statistical Computing, Vienna, Austria) and EZR (Saitama Medical Center, Jichi Medical University, Saitama, Japan), the latter of which is a graphical user interface for R. 


\section{Results}

\subsection{Patient Selection and MRI Assessment}

Among 1003 patients who underwent cholecystectomy after a diagnosis of AC, 394 underwent early cholecystectomy and 609 underwent delayed cholecystectomy. MRCP detected concomitant common bile duct stones (CBDS) in 160 (16.0\%) of 1003 patients, and all of them received two-stage treatment management and underwent delayed surgery. According to the 2013 Tokyo Guidelines recommendations [16], 130 of 159 patients who had been diagnosed with AC more than $72 \mathrm{~h}$ after onset underwent delayed surgery. Other reasons for a delay in surgery included severe comorbidities, cholangitis, pancreatitis, and a refusal to undergo early surgery. Of the 394 patients who underwent early cholecystectomy, 358 (90.1\%) had undergone preoperative MRI. While 323 patients underwent LC, 35 patients underwent planned open cholecystectomy by the surgeon's decision due to a history of previous abdominal surgery or radiological findings that indicated severe inflammation of the gallbladder. Two of 323 patients were excluded due to a gallbladder wall thickness of less than $3 \mathrm{~mm}$ on MRI. Ultimately, 321 patients were deemed eligible for inclusion. Following the MRI findings assessment, 103, 116, and 102 patients were included in the HSI, ISI, and LSI groups, respectively (Figure 2). Of 35 excluded patients with planned open surgery, 3, 14, and 18 patients showed HSI, ISI, and LSI on MRI, respectively.

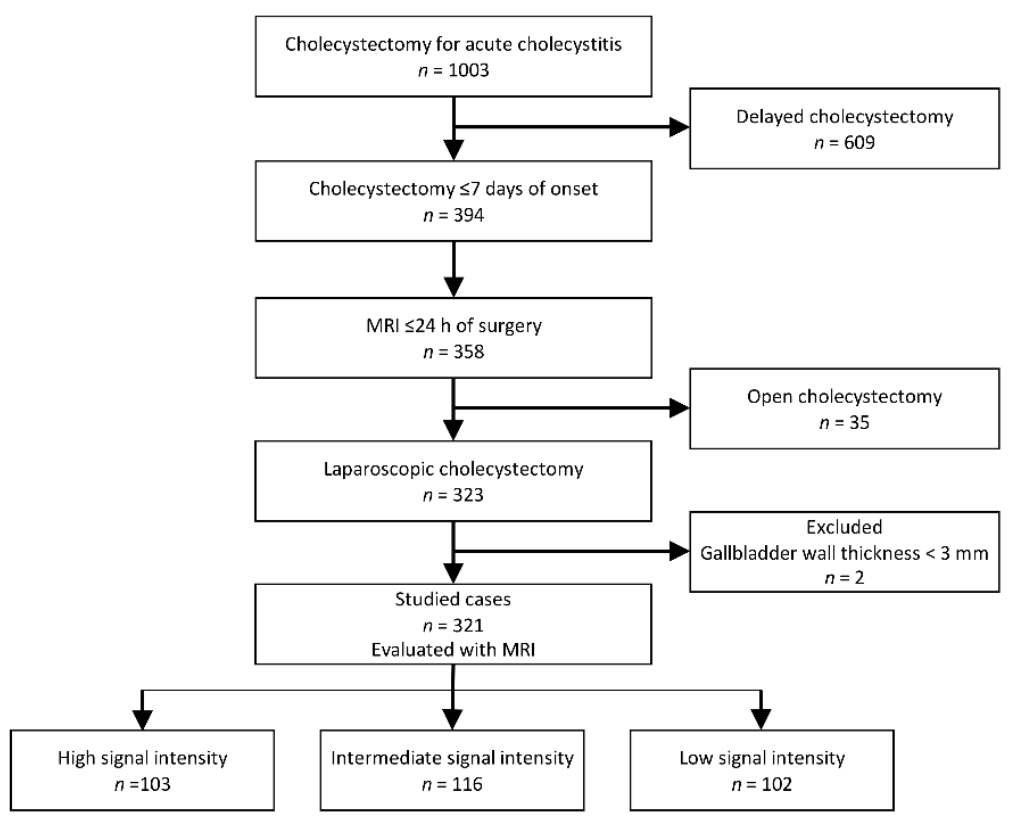

Figure 2. Study population diagram.

PHD anatomies were confirmed on MRCP in $315(98.1 \%)$ of 321 studied patients. Aberrant PHDs were detected in $23(7.2 \%)$ patients.

\subsection{Patient Characteristics in Each MRI Group}

The baseline patient characteristics and preoperative findings for the study population are shown in Table 1; there were no significant differences in patient characteristics. The rate of patients with severe inflammation findings on CT were significantly higher in the ISI $(0.0 \%)$ and LSI $(8.6 \%)$ groups than in the HSI (17.6\%) group based on a pairwise comparison ( $p=0.004$ (HSI vs. ISI), $p=0.067$ (ISI vs. LSI), and $p<0.001$ (LSI vs. HSI)). The rate of patients with fluid retention around the gallbladder on MRI was significantly higher, in decreasing order, in the LSI (52.9\%), ISI (31.9\%), and HSI $(16.5 \%)$ groups $(p=0.012$ (HSI vs. ISI), $p=0.007$ (ISI vs. LSI), and $p<0.001$ (LSI vs. HSI)). The preoperative WBC levels were significantly higher in the LSI group than in the HSI and ISI groups $(p=0.588$ (HSI vs. ISI), $p=0.007$ (ISI vs. LSI), and $p=0.002$ (LSI vs. HSI)). Preoperative CRP 
levels were significantly higher, in decreasing order, in the LSI (6.5 mg/dL (1.51-16.09)), ISI $(0.63 \mathrm{mg} / \mathrm{dL}(0.13-6.28])$, and HSI $(0.49 \mathrm{mg} / \mathrm{dL}(0.10-1.41))$ groups $(p=0.027$ (HSI vs. ISI), $p<0.001$ (ISI vs. LSI), and $p<0.001$ (LSI vs. HSI)). The number of patients who had undergone surgery within $48 \mathrm{~h}$ of disease onset was $90(87.4 \%)$ of $103,89(76.7 \%)$ of 116 , and $64(62.7 \%)$ of 102 in the HSI, ISI, and LSI groups, respectively ( $p=0.054$ (HSI vs. ISI), $p=0.054$ (ISI vs. LSI), and $p<0.001$ (LSI vs. HSI)). There were no significant differences in the experience profiles of the operators.

Table 1. Characteristics of the three groups.

\begin{tabular}{|c|c|c|c|c|c|}
\hline & \multicolumn{5}{|c|}{ Signal Intensity of the Gallbladder Wall on MRI } \\
\hline & All $(n=321)$ & HSI $(n=103)$ & ISI $(n=116)$ & LSI $(n=102)$ & $p$ Value \\
\hline Age (years) * & $62(49-72)$ & $60(46-71)$ & $62(50-72)$ & $64(56-75)$ & 0.061 \\
\hline \multicolumn{6}{|l|}{ Sex } \\
\hline Male & $214(66.7)$ & $60(58.3)$ & $84(72.4)$ & $70(68.6)$ & 0.079 \\
\hline Female & $107(33.3)$ & $43(41.7)$ & $32(27.6)$ & $32(31.4)$ & \\
\hline $\operatorname{BMI}\left(\mathrm{kg} / \mathrm{m}^{2}\right) *$ & $24.7(22.4-27.3)$ & $24.9(22.5-28.1)$ & $24.6(22.3-27.6)$ & $24.6(22.5-26.8)$ & 0.953 \\
\hline \multicolumn{6}{|l|}{ ASA physical status } \\
\hline I & $106(33.0)$ & $39(37.9)$ & $36(31.0)$ & $31(30.4)$ & 0.953 \\
\hline II & $192(59.8)$ & $60(58.3)$ & $70(60.3)$ & $62(60.8)$ & \\
\hline III & $23(7.2)$ & $4(3.9)$ & $10(9.8)$ & $9(8.8)$ & \\
\hline Diabetes mellitus & $54(16.8)$ & $17(16.5)$ & $19(16.4)$ & $18(17.6)$ & 0.964 \\
\hline Previous upper abdominal surgery & $11(3.4)$ & $3(2.9)$ & $3(2.6)$ & $5(4.9)$ & 0.691 \\
\hline Body temperature ${ }^{*}$ & $36.9(36.5-37.5)$ & $36.8(36.4-37.2)$ & $36.9(36.5-37.5)$ & $37.1(36.6-37.7)$ & 0.014 \\
\hline Severe inflammation findings on CT & $28(8.7)$ & $0(0.0)$ & $10(8.6)$ & $18(17.6)$ & $<0.001$ \\
\hline Thickness of gallbladder wall on MRI $(\mathrm{mm}) *$ & $7(5-8)$ & $6(4-8)$ & $7(6-8)$ & $7(6-9)$ & $<0.001$ \\
\hline Incarcerated stones in the gallbladder neck on MRI & $151(47.0)$ & $51(49.5)$ & $53(45.7)$ & $47(46.1)$ & 0.831 \\
\hline Fluid retention around the gallbladder on MRI & $108(33.6)$ & $17(16.5)$ & $37(31.9)$ & $54(52.9)$ & $<0.001$ \\
\hline $\mathrm{WBC}(/ \mu \mathrm{L}) *$ & $\begin{array}{c}12,140 \\
(9500-15,630)\end{array}$ & $\begin{array}{c}10,560 \\
(8310-14,225)\end{array}$ & $\begin{array}{c}11,130 \\
(8817-14,995)\end{array}$ & $\begin{array}{c}13,115 \\
(10,760-16,100)\end{array}$ & 0.001 \\
\hline $\mathrm{CRP}(\mathrm{mg} / \mathrm{dL}) *$ & $1.24(0.18-7.6)$ & $0.49(0.10-1.41)$ & $0.63(0.13-6.28)$ & $6.5(1.51-16.09)$ & $<0.001$ \\
\hline $\operatorname{AST}(\mathrm{U} / \mathrm{L}) *$ & $23(18-32)$ & $23(18-31)$ & $23(18-32)$ & $23(19-38)$ & 0.542 \\
\hline $\operatorname{ALT}(\mathrm{U} / \mathrm{L}) *$ & $24(16-40)$ & $24(16-38)$ & $22(16-41)$ & $27(17-46)$ & 0.404 \\
\hline $\mathrm{T}-\mathrm{Bil}(\mathrm{mg} / \mathrm{dL}) *$ & $0.9(0.6-1.5)$ & $0.7(0.6-1.1)$ & $1.0(0.6-1.6)$ & $1.1(0.8-1.7)$ & $<0.001$ \\
\hline $\mathrm{Alb}(\mathrm{g} / \mathrm{dL})^{*}$ & $4.1(3.8-4.4)$ & $4.2(4.0-4.4)$ & $4.1(3.8-4.4)$ & $4.0(3.6-4.2)$ & $<0.001$ \\
\hline \multicolumn{6}{|l|}{ Tokyo Guidelines Severity Grade } \\
\hline I & $250(77.9)$ & $93(90.3)$ & $93(80.2)$ & $64(62.7)$ & $<0.001$ \\
\hline II & $56(17.4)$ & $7(6.8)$ & $20(17.2)$ & $29(28.4)$ & \\
\hline III & $9(4.7)$ & $3(2.9)$ & $3(2.6)$ & $9(8.9)$ & \\
\hline \multicolumn{6}{|l|}{ Time between onset of disease and surgery } \\
\hline$\leq 48 \mathrm{~h}$ & $243(75.7)$ & $90(87.4)$ & $89(76.7)$ & $64(62.7)$ & $<0.001$ \\
\hline$>48 \mathrm{~h}$ & $78(24.3)$ & $13(12.6)$ & $27(23.3)$ & 38 (37.3) & \\
\hline \multicolumn{6}{|l|}{ Experience of the operator } \\
\hline$\leq 4$ years & $87(27.1)$ & $28(27.2)$ & $32(27.6)$ & $27(26.5)$ & 0.987 \\
\hline$\geq 5$ years & $234(72.9)$ & $75(72.8)$ & $84(72.4)$ & $75(73.5)$ & \\
\hline
\end{tabular}

Values in parentheses are percentages, unless indicated otherwise. * Values are medians (range). HSI, high signal intensity; ISI, intermediate signal intensity; LSI, low signal intensity. BMI, body mass index; ASA, American Society of Anesthesiologists; CT, computed tomography; MRI, magnetic resonance imaging; WBC, white blood cell; CRP, C-reactive protein; AST, aspartate aminotransferase; ALT, alanine aminotransferase; T-Bil, total bilirubin; Alb, albumin.

\subsection{Outcomes in Each MRI Group}

Overall, bailout procedures were performed in 79 (24.6\%) of 321 patients. Of these, conversions of the initial laparoscopic approach to open surgery and laparoscopic subtotal cholecystectomy were detected in $37(11.5 \%)$ and $42(13.1 \%)$ of 321 patients. The median operating time was $114 \mathrm{~min}$ (interquartile range: 88-144 min) (Table 2).

Table 2 shows the outcomes of the three groups. Bailout procedures were identified in $7(6.8 \%)$ of 103 patients in the HSI group, $31(26.7 \%)$ of 116 patients in the ISI group, and $41(40.2 \%)$ of 102 patients in the LSI group $(p<0.001)$. During the pairwise comparison, there were significant differences between each pair of groups ( $p<0.001$ (HSI vs. ISI), $p=0.043$ (ISI vs. LSI), and $p<0.001$ (LSI vs. HSI)). Conversion to open surgery was identified in zero $(0 \%)$ of 103 patients in the HSI group, $10(8.6 \%)$ of 116 patients in the ISI group, and $27(26.5 \%)$ of 102 patients in the LSI group ( $p=0.002$ (HSI vs. ISI), $p=0.001$ (ISI vs. LSI), and $p<0.001$ (LSI vs. HSI)). Laparoscopic subtotal cholecystectomy was 
detected in $7(6.8 \%)$ of 103 patients in the HSI group, $21(18.1 \%)$ of 116 patients in the ISI group, and $14(13.7 \%)$ of 102 patients in the LSI group ( $p=0.044$ (HSI vs. ISI), $p=0.461$ (ISI vs. LSI), and $p=0.225$ (LSI vs. HSI)).

Table 2. Surgical outcomes of the three groups.

\begin{tabular}{|c|c|c|c|c|c|}
\hline & \multicolumn{5}{|c|}{ Signal Intensity of the Gallbladder Wall on MRI } \\
\hline & $\operatorname{ALL}(n=321)$ & HSI $(n=103)$ & ISI $(n=116)$ & LSI $(n=102)$ & $p$ Value \\
\hline \multicolumn{6}{|l|}{ Surgical outcomes } \\
\hline Bailout procedures & $79(24.6)$ & $7(6.8)$ & $31(26.7)$ & $41(40.2)$ & $<0.001^{\dagger}$ \\
\hline Conversion to open surgery & $37(11.5)$ & $0(0.0)$ & $10(8.6)$ & $27(26.5)$ & $<0.001 \ddagger$ \\
\hline $\begin{array}{c}\text { Laparoscopic subtotal } \\
\text { cholecystectomy }\end{array}$ & $42(13.1)$ & $7(6.8)$ & $21(18.1)$ & $14(13.7)$ & $0.041^{\S}$ \\
\hline Operating time (minutes) * & $114(88-144)$ & $95(80-117)$ & $110(81-132)$ & $138(116-171)$ & $<0.001$ । । \\
\hline Blood loss $(\mathrm{mL}) *$ & $0(0-50)$ & $0(0-0)$ & $0(0-50)$ & $23(0-221)$ & $<0.001$ II \\
\hline Biliary injury & $2(0.6)$ & $0(0.0)$ & $0(0.0)$ & $2(2.0)$ & 0.100 \\
\hline $\begin{array}{l}\text { Accidental gallbladder injury } \\
\text { Intraoperative findings }\end{array}$ & $195(60.7)$ & $52(50.5)$ & $66(56.9)$ & $77(75.5)$ & $<0.001^{\#}$ \\
\hline \multicolumn{6}{|c|}{ Degree of inflammation assessed by the surgeon } \\
\hline Mild to moderate & $116(36.1)$ & $63(61.2)$ & $40(34.5)$ & $13(12.7)$ & $<0.001^{* *}$ \\
\hline Severe & $205(63.9)$ & $40(38.8)$ & $76(65.5)$ & $89(87.3)$ & \\
\hline \multicolumn{6}{|l|}{ Postoperative outcomes } \\
\hline Overall complications & $18(5.6)$ & $4(3.9)$ & $5(4.3)$ & $9(8.8)$ & 0.259 \\
\hline Major complications & $9(2.8)$ & $1(1.0)$ & $4(3.4)$ & $4(3.9)$ & 0.441 \\
\hline Reoperation & $0(0.0)$ & $0(0.0)$ & $0(0.0)$ & $0(0.0)$ & - \\
\hline Postoperative hospital stay * & $3(3-4)$ & $3(3-3)$ & $3(3-4)$ & $3(3-6)$ & $<0.001^{\dagger+}$ \\
\hline Readmission & $1(0.3)$ & $0(0.0)$ & $1(0.9)$ & $0(0.0)$ & 1.000 \\
\hline
\end{tabular}

LC, laparoscopic cholecystectomy; HSI, high signal intensity; ISI, intermediate signal intensity; LSI, low signal intensity. Values in parentheses are percentages, unless indicated otherwise. ${ }^{*}$ Values are medians (range). ${ }^{\dagger}$ In pairwise comparisons, $p<0.001$ (HSI vs. ISI), $p=0.043$ (ISI vs. LSI), and $p<0.001$ (LSI vs. HSI). ${ }^{\ddagger}$ In pairwise comparisons, $p=0.002$ (HSI vs. ISI), $p=0.001$ (ISI vs. LSI), and $p<0.001$ (LSI vs. HSI). ${ }^{\S}$ In pairwise comparisons, $p=0.044$ (HSI vs. ISI), $p=0.461$ (ISI vs. LSI), and $p=0.225$ (LSI vs. HSI). ${ }^{\prime \prime}$ In pairwise comparisons, $p=0.013$ (HSI vs. ISI), $p<0.001$ (ISI vs. LSI), and $p<0.001$ (LSI vs. HSI). ${ }^{\text {II }}$ In pairwise comparisons, $p=0.001$ (HSI vs. ISI), $p=0.001$ (ISI vs. LSI), and $p<0.001$ (LSI vs. HSI). " In pairwise comparisons, $p=0.415$ (HSI vs. ISI), $p=0.009$ (ISI vs. LSI), and $p<0.001$ (LSI vs. HSI). ${ }^{* *}$ In pairwise comparisons, $p<0.001$ (HSI vs. ISI), $p<0.001$ (ISI vs. LSI), and $p<0.001$ (LSI vs. HSI). ${ }^{+\dagger}$ In pairwise comparisons, $p=0.080$ (HSI vs. ISI), $p=0.007$ (ISI vs. LSI), and $p<0.001$ (LSI vs. HSI).

The median operating times were 95, 110, and 138 minutes in the HSI, ISI, and LSI groups, respectively $(p<0.001)$. In the pairwise comparisons, there was a significant difference between every pair of groups ( $p=0.013$ (HSI vs. ISI), $p<0.001$ (ISI vs. LSI), and $p<0.001$ (LSI vs. HSI)).

The amount of blood loss was small in each group (when the amount of blood loss was minimal, blood loss was counted as ' $0 \mathrm{~mL}$ '). Biliary injury occurred in two LSI patients, with no significant difference between the three groups in this regard. The rate of incidence of accidental gallbladder injury was significantly higher in the LSI group than in the HSI and ISI groups ( $p=0.415$ (HSI vs. ISI), $p<0.001$ (ISI vs. LSI), and $p<0.001$ (LSI vs. HSI)).

The rate of intraoperative findings of severe inflammation was significantly higher in the order of LSI (87.3\%), ISI (65.5\%), and LSI (38.8\%) $(p<0.001$ (HSI vs. ISI), $p<0.001$ (ISI vs. LSI), and $p<0.001$ (LSI vs. HSI)).

Additionally, the postoperative hospital stay was significantly longer in the LSI group than in the HSI and ISI groups ( $p=0.080$ (HSI vs. ISI), $p=0.007$ (ISI vs. LSI), and $p<0.001$ (LSI vs. HSI)), but the median values were similar. The rates of patients with overall complications and major complications were low in each group, and there were no significant differences between groups. Overall, only one patient in the ISI group was readmitted, and no patient underwent reoperation.

\subsection{Identification of Risk Factors for Bailout Procedures}

The univariate analysis identified eight risk factors $(p \leq 0.1)$ for bailout procedures: Severe inflammation findings on CT; the thickness of the gallbladder wall on MRI ( $\geq 8 \mathrm{~mm})$; 
fluid retention around the gallbladder on MRI; the signal intensity of the gallbladder wall on MRI; the CRP level ( $\geq 8.0 \mathrm{mg} / \mathrm{dL})$; the albumin level $(\leq 3.8 \mathrm{mg} / \mathrm{dL})$; Tokyo Guidelines severity grade II or III; and the time between onset and surgery $(>24 \mathrm{~h})$. In the multivariate analysis, ISI and LSI of the gallbladder wall on MRI (ISI vs. HSI, $p=0.004$, odds ratio (OR) $3.71,95 \%$ CI 1.51-9.10, and LSI vs. HSI, $p<0.001$, OR 5.30, 95\% CI 2.11-13.30) and the time between onset and surgery ( $>24 \mathrm{~h})(p=0.022$, OR $2.19,95 \%$ CI $1.12-4.29)$ were found to be independent risk factors for bailout procedures (Table 3). The final model showed a C-index of 0.77 (95\% CI 0.71-0.82).

Table 3. Univariate and multivariate analyses of risk factors for bailout procedures.

\begin{tabular}{|c|c|c|c|c|c|}
\hline \multirow[b]{2}{*}{ Variable } & \multirow[b]{2}{*}{ Category } & \multirow{2}{*}{$\begin{array}{l}\text { Number }(\%) \text { with } \\
\text { Bailout Procedures }\end{array}$} & \multirow{2}{*}{$\begin{array}{c}\begin{array}{c}\text { Univariate } \\
\text { Analysis }\end{array} \\
p \text { Value }\end{array}$} & \multicolumn{2}{|c|}{$\begin{array}{l}\text { Multivariate } \\
\text { Analysis }\end{array}$} \\
\hline & & & & OR $(95 \% \mathrm{CI})$ & $p$ Value \\
\hline \multirow[t]{2}{*}{ Age (years) } & $\geq 72$ & $24 / 81(29.6)$ & 0.235 & & \\
\hline & $<72$ & $55 / 240(22.9)$ & & & \\
\hline \multirow[t]{2}{*}{ Sex } & Male & $57 / 214(26.6)$ & 0.272 & & \\
\hline & Female & $22 / 107(20.6)$ & & & \\
\hline \multirow[t]{2}{*}{ BMI $\left(\mathrm{kg} / \mathrm{m}^{2}\right)$} & $\geq 30$ & $10 / 40(25.0)$ & 1.000 & & \\
\hline & $<30$ & $69 / 281(24.6)$ & & & \\
\hline \multirow[t]{2}{*}{ ASA physical status } & $\geq \mathrm{III}$ & $3 / 23(13.0)$ & 0.218 & & \\
\hline & $\leq \mathrm{II}$ & $76 / 298(25.5$ & & & \\
\hline \multirow[t]{2}{*}{ Diabetes mellitus } & $\bar{Y}$ es & $10 / 54(18.5)$ & 0.301 & & \\
\hline & No & $69 / 267(25.8)$ & & & \\
\hline \multirow[t]{2}{*}{ Past acute cholecystitis } & Yes & $6 / 19(31.6)$ & 0.425 & & \\
\hline & No & $73 / 302(24.2)$ & & & \\
\hline \multirow[t]{2}{*}{ Previous upper abdominal surgery } & Yes & $3 / 11(27.3)$ & 0.735 & & \\
\hline & No & $76 / 310(24.5)$ & & & \\
\hline \multirow[t]{2}{*}{ Body temperature $\left({ }^{\circ} \mathrm{C}\right)$} & $\geq 37.5$ & $23 / 83(27.7)$ & 0.461 & & \\
\hline & $<37.5$ & $56 / 238(23.5)$ & & & \\
\hline \multirow{2}{*}{ Severe inflammation findings on $\mathrm{CT}$ * } & Yes & $15 / 28(53.6)$ & 0.001 & $1.92(0.66-5.52)$ & 0.233 \\
\hline & No & $64 / 293(21.8)$ & & & \\
\hline \multirow{2}{*}{ Thickness of the gallbladder wall on MRI (mm) } & $\geq 8$ & $43 / 121(35.5)$ & $<0.001$ & $1.87(1.07-3.29)$ & 0.029 \\
\hline & $<8$ & $36 / 200(18.0)$ & & & \\
\hline \multirow{2}{*}{ Incarcerated stones in the gallbladder neck on MRI } & Yes & $37 / 151(24.5)$ & 1.000 & & \\
\hline & No & $24 / 170(23.5)$ & & & \\
\hline \multirow{3}{*}{ Fluid retention around the gallbladder on MRI } & Yes & $38 / 108(35.2)$ & 0.002 & $1.24(0.67-2.28)$ & 0.480 \\
\hline & No & $41 / 213(19.2)$ & & & \\
\hline & HSI & $7 / 103(6.8)$ & $<0.001$ & 1 & \\
\hline \multirow[t]{2}{*}{ Signal intensity of the gallbladder wall on MRI } & ISI & $31 / 116(26.7)$ & & $3.71(1.51-9.10)$ & 0.004 \\
\hline & LSI & $41 / 102(40.2)$ & & $5.30(2.11-13.3)$ & $<0.001$ \\
\hline \multirow[t]{2}{*}{$\mathrm{WBC}(/ \mu \mathrm{L})$} & $\geq 15,000$ & $28 / 95(29.5)$ & 0.203 & & \\
\hline & $<15,000$ & $51 / 226(22.6)$ & & & \\
\hline \multirow[t]{2}{*}{$\mathrm{CRP}(\mathrm{mg} / \mathrm{dL})$} & $\geq 8.0$ & $22 / 78(28.2)$ & $<0.001$ & $1.18(0.58-2.40)$ & 0.641 \\
\hline & $<8.0$ & $15 / 243(6.2)$ & & & \\
\hline \multirow[t]{2}{*}{ T-Bil (mg/dL) } & $\geq 1.5$ & $26 / 88(29.5)$ & 0.245 & & \\
\hline & $<1.5$ & $53 / 233(23.8)$ & & & \\
\hline \multirow[t]{2}{*}{$\mathrm{Alb}(\mathrm{g} / \mathrm{dL})$} & $\leq 3.8$ & $31 / 90(34.4)$ & 0.014 & $1.21(0.65-2.25)$ & 0.557 \\
\hline & $>3.8$ & $48 / 231(20.8)$ & & & \\
\hline \multirow[t]{2}{*}{ Tokyo Guidelines Severity Grade } & II, III & $28 / 71(39.4)$ & 0.002 & $0.985(0.43-2.28)$ & 0.972 \\
\hline & $\mathrm{I}$ & $51 / 250(20.4)$ & & & \\
\hline \multirow[t]{2}{*}{ Time between onset and surgery (hours) } & $>24$ & $64 / 205(31.2)$ & $<0.001$ & $2.19(1.12-4.29)$ & 0.022 \\
\hline & $\leq 24$ & $15 / 116(12.9)$ & & & \\
\hline \multirow[t]{2}{*}{ Experience of the operator (years) } & $\leq 4$ & $22 / 87(25.3)$ & 0.885 & & \\
\hline & $\geq 5$ & $57 / 234(24.4)$ & & & \\
\hline
\end{tabular}

OR, odds ratio; BMI, body mass index; ASA, American Society of Anesthesiologists; CT, computed tomography; MRI, magnetic resonance imaging; WBC, white blood cell; HSI, high signal intensity; ISI, intermediate signal intensity; LSI, low signal intensity; CRP, C-reactive protein; T-Bil, total bilirubin; Alb, albumin. * irregular thickening of the gallbladder wall, poor contrast enhancement of the gallbladder wall, increased density of fatty tissue around the gallbladder, membranous structures within the lumen, or perigallbladder abscess.

\subsection{Identification of Risk Factors for Prolonged Operation}

Based on the data collected from the overall study population, a prolonged operating time was defined as $144 \mathrm{~min}$ or longer. During the univariate analysis, eight risk factors $(p<0.1)$ for a prolonged operating time $(\geq 44 \mathrm{~min})$ were detected: Severe inflammation findings on CT; thickness of the gallbladder wall on MRI ( $\geq 8 \mathrm{~mm})$; fluid retention around 
the gallbladder on MRI; the signal intensity of the gallbladder wall on MRI; the CRP level $(\geq 8.0 \mathrm{mg} / \mathrm{dL})$; the albumin level $(\leq 3.8 \mathrm{mg} / \mathrm{dL})$; Tokyo Guidelines severity grade II or III; and operator experience ( $\leq 4$ years). In the multivariate analysis, LSI of the gallbladder wall on MRI (LSI vs. HSI, $p<0.001$, OR 6.10,95\% CI 2.74-13.60) and operator experience ( $\leq 4$ years) ( $p=0.022$, OR $2.03,95 \%$ CI 1.11-3.71) were identified as independent risk factors for a prolonged operating time ( $\geq 144$ minutes) (Table 4$)$. The final model showed a C-index of 0.75 (95\% CI $0.69-0.81)$.

Table 4. Univariate and multivariate analyses of risk factors for prolonged surgery.

\begin{tabular}{|c|c|c|c|c|c|}
\hline \multirow[b]{2}{*}{ Variable } & \multirow[b]{2}{*}{ Category } & \multirow{2}{*}{$\begin{array}{c}\text { Number }(\%) \\
\text { with Prolonged } \\
\text { Surgery }\end{array}$} & \multirow{2}{*}{$\begin{array}{c}\begin{array}{c}\text { Univariate } \\
\text { Analysis }\end{array} \\
p \text { Value }\end{array}$} & \multicolumn{2}{|c|}{$\begin{array}{c}\text { Multivariate } \\
\text { Analysis }\end{array}$} \\
\hline & & & & OR $(95 \% \mathrm{CI})$ & $p$ Value \\
\hline \multirow[t]{2}{*}{ Age (years) } & $\geq 72$ & $22 / 81(27.2)$ & 0.659 & & \\
\hline & $<72$ & $59 / 240(24.6)$ & & & \\
\hline \multirow[t]{2}{*}{ Sex } & Male & $57 / 214(26.6)$ & 0.496 & & \\
\hline & Female & $24 / 107(22.4)$ & & & \\
\hline \multirow[t]{2}{*}{$\operatorname{BMI}\left(\mathrm{kg} / \mathrm{m}^{2}\right)$} & $\geq 30$ & $9 / 40(22.5)$ & 0.846 & & \\
\hline & $<30$ & $72 / 281(25.6)$ & & & \\
\hline \multirow[t]{2}{*}{ ASA physical status } & $\geq \mathrm{III}$ & $6 / 23(26.1)$ & 1.000 & & \\
\hline & $\leq \mathrm{II}$ & $75 / 298(25.2)$ & & & \\
\hline \multirow[t]{2}{*}{ Diabetes mellitus } & Yes & $9 / 54(16.7)$ & 0.125 & & \\
\hline & No & $72 / 267(27.0)$ & & & \\
\hline \multirow[t]{2}{*}{ Past acute cholecystitis } & Yes & $3 / 19(15.8)$ & 0.422 & & \\
\hline & No & $78 / 302(25.8)$ & & & \\
\hline \multirow[t]{2}{*}{ Previous upper abdominal surgery } & Yes & $1 / 11(9.1)$ & 0.302 & & \\
\hline & No & $80 / 310(25.8)$ & & & \\
\hline \multirow[t]{2}{*}{ Body temperature $\left({ }^{\circ} \mathrm{C}\right)$} & $\geq 37.5$ & $27 / 88(30.7)$ & 0.195 & & \\
\hline & $<37.5$ & $54 / 233(23.2)$ & & & \\
\hline \multirow{2}{*}{ Severe inflammation findings on $\mathrm{CT}^{*}$} & Yes & $12 / 28(42.9)$ & 0.038 & $0.90(0.31-2.65)$ & 0.854 \\
\hline & No & $69 / 293(23.5)$ & & & \\
\hline \multirow{2}{*}{ Thickness of the gallbladder wall on MRI (mm) } & $\geq 8$ & $40 / 121(33.1)$ & 0.017 & $1.64(0.93-2.89)$ & 0.087 \\
\hline & $<8$ & $41 / 200(20.5)$ & & & \\
\hline \multirow{2}{*}{ Incarcerated stones in the gallbladder neck on MRI } & Yes & $36 / 151(23.8)$ & 0.609 & & \\
\hline & No & $45 / 170(26.5)$ & & & \\
\hline \multirow{3}{*}{ Fluid retention around the gallbladder on MRI } & Yes & $37 / 108(34.3)$ & 0.010 & $1.17(0.64-2.15)$ & 0.612 \\
\hline & No & $44 / 214(20.7)$ & & & \\
\hline & HSI & $11 / 103(10.7)$ & $<0.001$ & 1 & \\
\hline \multirow[t]{2}{*}{ Signal intensity of the gallbladder wall on MRI } & ISI & $22 / 116(19.0)$ & & $1.72(0.77-3.85)$ & 0.184 \\
\hline & LSI & $48 / 102(47.1)$ & & $6.10(2.74-13.60)$ & $<0.001$ \\
\hline \multirow[t]{2}{*}{$\mathrm{WBC}(/ \mu \mathrm{L})$} & $\geq 15,000$ & $27 / 95(28.4)$ & 0.401 & & \\
\hline & $<15,000$ & $54 / 226(23.9)$ & & & \\
\hline \multirow[t]{2}{*}{$\mathrm{CRP}(\mathrm{mg} / \mathrm{dL})$} & $\geq 8.0$ & $29 / 78(37.2)$ & 0.007 & $1.08(0.54-2.18)$ & 0.828 \\
\hline & $<8.0$ & $52 / 243(21.4)$ & & & \\
\hline \multirow[t]{2}{*}{ T-Bil (mg/dL) } & $\geq 1.5$ & $22 / 88(25.0)$ & 1.000 & & \\
\hline & $<1.5$ & $59 / 233(25.3)$ & & & \\
\hline \multirow[t]{2}{*}{$\mathrm{Alb}(\mathrm{g} / \mathrm{dL})$} & $\leq 3.8$ & $29 / 90(32.2)$ & 0.086 & $1.05(0.55-1.98)$ & 0.888 \\
\hline & $>3.8$ & $52 / 231(22.5)$ & & & \\
\hline \multirow[t]{2}{*}{ Tokyo Guidelines Severity Grade } & II, III & $27 / 71(38.0)$ & 0.008 & $1.31(0.57-2.99)$ & 0.514 \\
\hline & I & $54 / 250(21.6)$ & & & \\
\hline \multirow[t]{2}{*}{ Time between onset and surgery (hours) } & $>24$ & $29 / 116(25.0)$ & 1.000 & & \\
\hline & $\leq 24$ & $52 / 205(25.4)$ & & & \\
\hline \multirow[t]{2}{*}{ Experience of the operator (years) } & $\leq 4$ & $29 / 87(33.3)$ & 0.045 & $2.03(1.11-3.71)$ & 0.022 \\
\hline & $\geq 5$ & $52 / 234(22.2)$ & & & \\
\hline
\end{tabular}

OR, odds ratio; BMI, body mass index; ASA, American Society of Anesthesiologists; CT, computed tomography; MRI, magnetic resonance imaging; WBC, white blood cell; HSI, high signal intensity; ISI, intermediate signal intensity; LSI, low signal intensity; CRP, C-reactive protein; T-Bil, total bilirubin; Alb, albumin. * irregular thickening of the gallbladder wall, poor contrast enhancement of the gallbladder wall, increased density of fatty tissue around the gallbladder, membranous structures within the lumen, or perigallbladder abscess. 


\section{Discussion}

This single-center retrospective study has presented two major novel findings for the surgical management of AC. First, LSI progression of the gallbladder wall in AC was significantly associated with a higher rate of bailout procedures, such as open conversion and laparoscopic subtotal cholecystectomy, and prolonged operating times. Second, the LSI of the gallbladder wall on MRI was the only independent risk factor for both bailout procedures and a prolonged operating time. Our results indicate that preoperative assessment of the signal intensity of the gallbladder wall on MRI is a novel and useful predictor for surgical difficulty during LC for AC. The routine assessment of MRCP and HASTE MRI at the time of AC diagnosis could provide surgeons with useful information for performing a safe surgery and provide appropriate surgical management in a limited time before subsequent early LC.

The overall open conversion rate was $11.5 \%$, and the median operating time was $114 \mathrm{~min}$. These findings were similar to those in previous studies in which early LCs were performed for AC [32-35]. As we hypothesized, LSI broadening in the gallbladder wall on preoperative MRI was significantly associated with a higher bailout procedure rate and longer operating time in early LC for AC. These results can be explained by the results of our previous study, which showed that the rate of inflammatory pathological changes such as necrosis, abscess formation, and fibrosis of the gallbladder wall significantly increased as LSI in the gallbladder wall broadened $(27.4 \%, 84.8 \%$, and $97.1 \%$ in the HSI, ISI, and LSI groups, respectively) [12]. There was a significant difference in operative outcomes between the HSI and LSI groups (bailout procedure rate: $6.8 \%$ vs. $40.2 \%$; open conversion rate: $0 \%$ vs. $26.5 \%$; operating time: $95 \mathrm{~min}$ vs. $138 \mathrm{~min}$ ). Considering that less operator experience was an independent risk factor for prolonged surgery, it is recommended that a well-experienced surgeon conduct the operation for AC with LSI on MRI.

Previous studies have identified numerous risk factors for difficult LC, such as an advanced age, a male sex, the BMI, the American Society of Anesthesiologists physical status score, diabetes, previous abdominal surgery, gallbladder wall thickening, incarcerated stones in the gallbladder neck, fluid retention around the gallbladder, the body temperature, elevated WBCs, the CRP level, a low albumin level, a high bilirubin level, Tokyo Guidelines severity grade II/III AC, and elapsed time before surgery [17-27]. However, broadened LSI of the gallbladder wall on MRI was the only independent risk factor for both the bailout procedure and a prolonged operating time of LC for AC in the present study. We also assessed severe inflammation findings on $\mathrm{CT}$, but they were not independent risk factors in the multivariate analysis. These results indicate that the assessment with MRCP better predicts difficult $\mathrm{LC}$ than preoperative $\mathrm{CT}$ or other previously reported risk factors.

MRCP detected CBDS in 16\% of patients diagnosed with AC, which affected their treatment strategy. MRCP/MRI was performed in more than $90 \%$ of patients who underwent early cholecystectomy for AC, and PHD anatomies were confirmed in as many as $98 \%$ of these patients in the present study. These results were similar to those of previous studies [7-10]. Preoperative MRCP is a standard method for assessing the biliary anatomy before LC, not only for adult patients, but also pediatric patients who more often have anatomical variations [36]. The Tokyo Guidelines recommend that most patients with acute cholecystitis have early LC and that early LC should be performed before necrosis and fibrosis progress over time and the surgical difficulty increases [2,37]. After diagnosing AC, surgeons need to assess the surgical risk of subsequent LC, but often have limited time for examinations, especially in emergencies. Our results show that MRI is useful not only for assessing the presence of CBDS and biliary anatomy, but also for predicting the surgical difficulty due to inflammation. Although MRI is more expensive than other examinations, such as abdominal ultrasonography [37], it provides much information at once. Our MRI assessment method is available using the HASTE sequence captured during routine MRCP, as some studies have already reported $[11,12,38,39]$, and can be quickly introduced as part of daily radiological studies. In conclusion, MRCP/MRI could be a useful option 
for the comprehensive surgical management of acute cholecystitis and decision making in emergencies.

Several limitations of the present study should be acknowledged. First, this was a retrospective and single-institution study. The criteria for bailout procedures varied among surgeons, and the operative time was largely dependent on the operator's skills and experience. Additionally, some patients with a history of previous abdominal surgery or who had radiological findings that indicate severe inflammation of the gallbladder underwent planned open cholecystectomy based on the surgeon's decision. Second, most of the patients diagnosed with AC more than $72 \mathrm{~h}$ after onset underwent delayed surgery following the 2013 Tokyo Guidelines [16]. Further validations such as prospective studies are needed regarding patients diagnosed as having AC more than $72 \mathrm{~h}$ after onset.

Author Contributions: Conceptualization, K.O. and K.H.; methodology K.O. and T.A.; validation, T.Y.; formal analysis, K.O. and M.F. (Masahide Fukaya); investigation K.O., K.H., Y.S., and A.A.; resources, T.K.; data curation, K.O. and M.F. (Masahiro Fujii); writing-original draft preparation, K.O.; writing-review and editing, K.H., M.F. (Masahide Fukaya), and Y.S.; visualization, K.O.; supervision, K.H.; project administration, T.K. All authors have read and agreed to the published version of the manuscript.

Funding: This research received no external funding.

Institutional Review Board Statement: The study was conducted according to the guidelines of the Declaration of Helsinki, and approved by the Ethics Committee of Toyohashi Municipal Hospital (approval number 569, date of approval: 2 December 2020).

Informed Consent Statement: Patient consent was waived due to retrospective nature of the study. Opt-out method was applied to obtain consent on this study.

Data Availability Statement: The data that support the findings of this study are available from the corresponding author (K.O.) upon reasonable request, due to restrictions of privacy.

Acknowledgments: The authors are grateful to M. Maeda (pathologist), who prepared the pathological reports at Toyohashi Municipal Hospital.

Conflicts of Interest: The authors declare no conflict of interest.

\section{References}

1. Okamoto, K.; Suzuki, K.; Takada, T.; Strasberg, S.M.; Asbun, H.J.; Endo, I.; Yamamoto, M. Tokyo Guidelines 2018: Flowchart for the manage-ment of acute cholecystitis. J. Hepato Biliary Pancreatic Sci. 2018, 2, 55-72. [CrossRef]

2. Wakabayashi, G.; Iwashita, Y.; Hibi, T.; Takada, T.; Strasberg, S.M.; Asbun, H.J.; Endo, I.; Umezawa, A.; Asai, K.; Suzuki, K.; et al. Tokyo Guidelines 2018: Surgical management of acute cholecystitis: Safe steps in laparoscopic cholecystectomy for acute cholecystitis (with videos). J. Hepato Biliary Pancreatic Sci. 2018, 25, 73-86. [CrossRef] [PubMed]

3. Flum, D.R.; Dellinger, E.P.; Cheadle, A.; Chan, L.; Koepsell, T. Intraoperative Cholangiography and Risk of Common Bile Duct Injury during Cholecystectomy. JAMA 2003, 289, 1639-1644. [CrossRef] [PubMed]

4. Seibert, D.; Matulis, S.R.; Griswold, F. A rare right hepatic duct anatomical variant discovered after laparoscopic bile duct transection. Surg. Laparosc. Endosc. 1996, 2, 61-64. [CrossRef]

5. Adamsen, S.; Hansen, O.H.; Funch-Jensen, P.; Schulze, S.; Stage, J.G.; Wara, P. Bile duct injury during laparoscopic cholecystectomy: A prospective nationwide series. J. Am. Coll. Surg. 1997, 2, 571-578.

6. Hugh, T.B. New strategies to prevent laparoscopic bile duct injury-Surgeons can learn from pilots. Surgery 2002, 132, 826-835. [CrossRef]

7. Peng, W.K.; Sheikh, Z.; Nixon, S.J.; Paterson-Brown, S. Role of laparoscopic cholecystectomy in the early management of acute gallbladder disease. BJS 2005, 92, 586-591. [CrossRef]

8. Nebiker, C.A.; Baierlein, S.A.; Beck, S.; Von Flüe, M.; Ackermann, C.; Peterli, R. Is routine MR cholangiopancreatography (MRCP) justified prior to cholecystectomy? Langenbeck's Arch. Surg. 2008, 394, 1005-1010. [CrossRef]

9. Wong, H.-P.; Chiu, Y.-L.; Shiu, B.-H.; Ho, L.-C. Preoperative MRCP to detect choledocholithiasis in acute calculous cholecystitis. J. Hepato Biliary Pancreatic Sci. 2012, 19, 458-464. [CrossRef]

10. Kurata, M.; Honda, G.; Okuda, Y.; Kobayashi, S.; Sakamoto, K.; Iwasaki, S.; Chiba, K.; Tabata, T.; Kuruma, S.; Kamisawa, T. Preoperative detection and handling of aberrant right posterior sectoral hepatic duct during laparoscopic cholecystectomy. J. Hepato Biliary Pancreatic Sci. 2015, 22, 558-562. [CrossRef]

11. Jung, S.E.; Lee, J.M.; Lee, K.; Rha, S.E.; Choi, B.G.; Kim, E.K.; Hahn, S.T. Gallbladder wall thickening: MR imaging and pathologic correla-tion with emphasis on layered pattern. Eur. Radiol. 2005, 2, 694-701. [CrossRef] 
12. Omiya, K.; Hiramatsu, K.; Kato, T.; Shibata, Y.; Yoshihara, M.; Aoba, T.; Arimoto, A.; Ito, A. Preoperative MRI for predicting pathological changes associated with surgical difficulty during laparoscopic cholecystectomy for acute cholecystitis. BJS Open 2020, 4, 1137-1145. [CrossRef]

13. Hirota, M.; Takada, T.; Kawarada, Y.; Nimura, Y.; Miura, F.; Hirata, K.; Mayumi, T.; Yoshida, M.; Strasberg, S.; Pitt, H.; et al. Diagnostic criteria and severity assessment of acute cholecystitis: Tokyo Guidelines. J. Hepato Biliary Pancreatic Surg. 2007, 14, 78-82. [CrossRef]

14. Yokoe, M.; Takada, T.; Strasberg, S.M.; Solomkin, J.S.; Mayumi, T.; Gomi, H.; Pitt, H.A.; Garden, O.J.; Kiriyama, S.; Hata, J.; et al. TG13 diagnostic criteria and severity grading of acute cholecystitis (with videos). J. Hepato Biliary Pancreatic Sci. 2013, $20,35-46$. [CrossRef]

15. Yokoe, M.; Hata, J.; Takada, T.; Strasberg, S.M.; Bun, T.A.Y.; Wakabayashi, G.; Kozaka, K.; Endo, I.; DeZiel, D.J.; Miura, F.; et al. Tokyo Guidelines 2018: Diagnostic criteria and severity grading of acute cholecystitis (with videos). J. Hepato Biliary Pancreatic Sci. 2018, 25, 41-54. [CrossRef] [PubMed]

16. Yamashita, Y.; Takada, T.; Strasberg, S.M.; Pitt, H.A.; Gouma, D.J.; Garden, O.J.; Supe, A.N. TG13 surgical management of acute cholecystitis. J. Hepato Biliary Pancreatic Sci. 2013, 2, 89-96. [CrossRef] [PubMed]

17. Zhu, B.; Zhang, Z.; Wang, Y.; Gong, K.; Lu, Y.; Zhang, N. Comparison of Laparoscopic Cholecystectomy for Acute Cholecystitis within and Beyond $72 \mathrm{~h}$ of Symptom Onset During Emergency Admissions. World J. Surg. 2012, 36, 2654-2658. [CrossRef]

18. Terho, P.M.; Leppäniemi, A.K.; Mentula, P.J. Laparoscopic cholecystectomy for acute calculous cholecystitis: A retrospective study assessing risk factors for conversion and complications. World J. Emerg. Surg. 2016, 11, 1-9. [CrossRef] [PubMed]

19. Shamiyeh, A.; Danis, J.; Wayand, W.; Zehetner, J. A 14-year analysis of laparoscopic cholecystectomy: Conversion-When and why? Surg. Laparosc. Endosc. Percutan. Tech. 2007, 2, 271-276. [CrossRef]

20. Sakuramoto, S.; Sato, S.; Okuri, T.; Sato, K.; Hiki, Y.; Kakita, A. Preoperative evaluation to predict technical difficulties of laparo-scopic cholecystectomy on the basis of histological inflammation findings on resected gallbladder. Am. J. Surg. 2000, 2, 114-121. [CrossRef]

21. Philip Rothman, J.; Burcharth, J.; Pommergaard, H.C.; Viereck, S.; Rosenberg, J. Preoperative Risk Factors for Conversion of Laparoscopic Cholecystectomy to Open Surgery-A Systematic Review and Meta-Analysis of Observational Studies. Dig. Surg. 2016, 2, 414-423. [CrossRef] [PubMed]

22. Low, J.K.; Barrow, P.; Owera, A.; Ammori, B.J. Timing of laparoscopic cholecystectomy for acute cholecystitis: Evidence to sup-port a proposal for an early interval surgery. Am. Surg. 2007, 2, 1188-1192. [CrossRef]

23. Hiromatsu, T.; Hasegawa, H.; Sakamoto, E.; Komatsu, S.; Kawai, K.; Tabata, T. Preoperative evaluation of difficulty on laparoscopic cholecystectomy (in Japanese). Jpn. Gastroenterol. Surg. 2007, 40, 1449-1455. [CrossRef]

24. Ćwik, G.; Skoczylas, T.; Wyroślak-Najs, J.; Wallner, G. The value of percutaneous ultrasound in predicting conversion from laparoscopic to open cholecystectomy due to acute cholecystitis. Surg. Endosc. 2013, 27, 2561-2568. [CrossRef] [PubMed]

25. Cho, K.S.; Baek, S.Y.; Kang, B.C.; Choi, H.-Y.; Han, H.-S. Evaluation of preoperative sonography in acute cholecystitis to predict technical difficulties during laparoscopic cholecystectomy. J. Clin. Ultrasound 2004, 32, 115-122. [CrossRef]

26. Cho, J.Y.; Han, H.-S.; Yoon, Y.-S.; Ahn, K.S.; Lee, S.H.; Hwang, J.-H. Hepatobiliary Scan for Assessing Disease Severity in Patients with Cholelithiasis. Arch. Surg. 2011, 146, 169. [CrossRef]

27. Ambe, P.C.; Christ, H.; Wassenberg, D. Does the Tokyo guidelines predict the extent of gallbladder inflammation in patients with acute cholecystitis? A single center retrospective analysis. BMC Gastroenterol. 2015, 15, 1-8. [CrossRef]

28. Bennett, G.L.; Rusinek, H.; Lisi, V.; Israel, G.M.; Krinsky, G.A.; Slywotzky, C.M.; Megibow, A. CT Findings in Acute Gangrenous Cholecystitis. Am. J. Roentgenol. 2002, 178, 275-281. [CrossRef]

29. Utsumi, M.; Aoki, H.; Kunitomo, T.; Mushiake, Y.; Yasuhara, I.; Taniguchi, F.; Arata, T.; Katsuda, K.; Tanakaya, K.; Takeuchi, H. Preoperative Risk Factors for Conversion of Laparoscopic Cholecystectomy to Open Cholecystectomy and the Usefulness of the 2013 Tokyo Guidelines. Acta Med. Okayama 2017, 71, 419-425.

30. Sato, N.; Yabuki, K.; Shibao, K.; Mori, Y.; Tamura, T.; Higure, A.; Yamaguchi, K. Risk factors for a prolonged operative time in a sin-gle-incision laparoscopic cholecystectomy. HPB 2014, 16, 177-182. [CrossRef]

31. Bickel, A.; Rappaport, A.; Hazani, E.; Eitan, A. Laparoscopic Cholecystectomy for Acute Cholecystitis Performed by Residents in Surgery: A Risk Factor for Conversion to Open Laparotomy? J. Laparoendosc. Adv. Surg. Tech. 1998, 8, 137-141. [CrossRef] [PubMed]

32. Lo, C.M.; Liu, C.L.; Fan, S.T.; Lai, E.C.; Wong, J. Prospective randomized study of early versus delayed laparoscopic cholecystectomy for acute cholecystitis. Ann. Surg. 1998, 2, 461-467. [CrossRef]

33. Lai, P.B.; Kwong, K.H.; Leung, K.L.; Kwok, S.P.; Chan, A.C.; Chung, S.C.; Lau, W.Y. Randomized trial of early versus delayed laparoscopic cholecystectomy for acute cholecystitis. BJS 1998, 85, 764-767. [CrossRef] [PubMed]

34. Kolla, S.B.; Aggarwal, S.; Kumar, A.; Kumar, R.; Chumber, S.; Parshad, R.; Seenu, V. Early versus delayed laparoscopic cholecystecto-my for acute cholecystitis: A prospective randomized trial. Surg Endosc. 2004, 2, 1323-1327. [CrossRef]

35. Gutt, C.N.; Encke, J.; Koninger, J.; Harnoss, J.C.; Weigand, K.; Kipfmuller, K.; Büchler, M.W. Acute cholecystitis: Early versus delayed chol-ecystectomy, a multicenter randomized trial (ACDC study, NCT00447304). Ann. Surg. 2013, 258, 385-393. [CrossRef] [PubMed]

36. Pogorelic, Z.; Aralica, M.; Jukic, M.; Zitko, V.; Despot, R.; Juric, I. Gallbladder Disease in Children: A 20-year Single-center Expe-rience. Indian Pediatr. 2019, 2, 384-386. [CrossRef] 
37. Ansaloni, L.; Pisano, M.; Coccolini, F.; Peitzmann, A.B.; Fingerhut, A.; Catena, F.; Agresta, F.; Allegri, A.; Bailey, I.; Balogh, Z.J.; et al. 2016 WSES guidelines on acute calculous cholecystitis. World J. Emerg. Surg. 2016, 11, 1-23. [CrossRef]

38. Watanabe, Y.; Nagayama, M.; Okumura, A.; Amoh, Y.; Katsube, T.; Suga, T.; Koyama, S.; Nakatani, K.; Dodo, Y. MR Imaging of Acute Biliary Disorders. Radiographics 2007, 27, 477-495. [CrossRef] [PubMed]

39. Regan, F.; Schaefer, D.C.; Smith, D.P.; Petronis, J.D.; Bohlman, M.E.; Magnuson, T.H. The Diagnostic Utility of HASTE MRI in the Evaluation of Acute Cholecystitis. J. Comput. Assist. Tomogr. 1998, 22, 638-642. [CrossRef] 